Article

\title{
Sarcopenia and Ghrelin System in the Clinical Outcome and Prognosis of Gastroenteropancreatic Neuroendocrine Neoplasms
}

Yiraldine Herrera-Martínez ${ }^{1}$, Carlos Alzas Teomiro ${ }^{2,3}$, Soraya León Idougourram ${ }^{2,3}$, María José Molina Puertas ${ }^{2,3}$, Alfonso Calañas Continente 2,3, Raquel Serrano Blanch 2,4 , Justo P. Castaño 2,5,6 ${ }^{\mathbb{D}}$, María Ángeles Gálvez Moreno ${ }^{2,3}$, Manuel D. Gahete ${ }^{2,5,6}$, Raúl M. Luque ${ }^{2,5,6}$ and Aura D. Herrera-Martínez 2,3,*

check for

updates

Citation: Herrera-Martínez, Y.; Alzas

Teomiro, C.; León Idougourram, S.;

Molina Puertas, M.J.;

Calañas Continente, A.; Serrano

Blanch, R.; Castaño, J.P.; Gálvez

Moreno, M.Á.; Gahete, M.D.

Luque, R.M.; et al. Sarcopenia and

Ghrelin System in the Clinical

Outcome and Prognosis of

Gastroenteropancreatic

Neuroendocrine Neoplasms. Cancers 2022, 14, 111. https://doi.org/

10.3390/cancers14010111

Academic Editor:

Hendrik Ungefroren

Received: 2 November 2021

Accepted: 13 December 2021

Published: 27 December 2021

Publisher's Note: MDPI stays neutral with regard to jurisdictional claims in published maps and institutional affiliations.

Copyright: (C) 2021 by the authors. Licensee MDPI, Basel, Switzerland. This article is an open access article distributed under the terms and conditions of the Creative Commons Attribution (CC BY) license (https:// creativecommons.org/licenses/by/ $4.0 /)$.
1 Department of Nuclear Medicine, Virgen del Rocio University Hospital, 41013 Seville, Spain; gerah10@gmail.com

2 Maimonides Institute for Biomedical Research of Cordoba (IMIBIC), Reina Sofia University Hospital, 14004 Cordova, Spain; carlosalzas@hotmail.com (C.A.T.); sorayaleon@gmail.com (S.L.I.); cmmolina@hotmail.com (M.J.M.P.); acalanas@hotmail.com (A.C.C.); rserrano@hotmail.com (R.S.B.); justocastano@gmail.com (J.P.C.); mariaagalvez@juntadeandalcia.es (M.Á.G.M.); bc2gaorm@uco.es (M.D.G.); bc2luhur@uco.es (R.M.L.)

3 Endocrinology and Nutrition Service, Reina Sofia University Hospital, 14004 Cordova, Spain

4 Medical Oncology Service, Reina Sofia University Hospital, 14004 Cordova, Spain

5 Department of Cell Biology, Physiology, and Immunology, University of Córdoba, 14014 Cordova, Spain

6 CIBER Fisiopatología de la Obesidad y Nutrición (CIBERobn), Instituto de Salud Carlos III, 14004 Cordova, Spain

* Correspondence: aurita.dhm@gmail.com

Simple Summary: Malnutrition and sarcopenia affect clinical outcomes in cancer patients. Nutritional evaluation in patients with neuroendocrine neoplasms (NENs) is not routinely performed. Currently, the evaluation of sarcopenia using CT scans is the gold standard in cancer patients, additionally, anthropometric, biochemical and molecular analysis of patients with gastroenteropancreatic NENs at diagnosis was perfomed. The expression levels of key ghrelin system components were assessed in 63 tumor samples. Results: Nutritional parameters were similar in GEP-NEN tumors of different origin. Relapsed disease was associated with decreased BMI. Patients who presented with weight loss at diagnosis had significantly lower overall survival (108 (25-302) vs. 263 (79-136) months). Ghrelin O-acyltransferase (GOAT) enzyme expression was higher in these patients. The prevalence of sarcopenia using CT images reached $87.2 \%$. Mortality was observed only in patients with sarcopenia. Muscle evaluation was correlated with biochemical parameters but not with the expression of ghrelin system components. Conclusion: Survival is related to the nutritional status of patients with GEP-NENs and also to the molecular expression of some relevant ghrelin system components. Routine nutritional evaluation should be performed in these patients, in order to prescribe appropriate nutritional support, when necessary, for increasing quality of life and improving clinical outcomes.

Abstract: Background: Malnutrition and sarcopenia affect clinical outcomes and treatment response in cancer patients. Patients with neuroendocrine neoplasms (NENs) may present with additional symptoms related to tumor localization in the gastrointestinal tract and hormone secretion, increasing the risk and effects of sarcopenia. Aim: To explore the presence of malnutrition and sarcopenia in gastroenteropancreatic (GEP)-NEN patients, their relation to tumor characteristics, patient outcomes, survival and the molecular expression of ghrelin system components in the tumor. Patients and methods: One-hundred-and-four patients were included. Anthropometric, biochemical and CT-scans at diagnosis were evaluated. The expression levels of key ghrelin system components were assessed in 63 tumor samples. Results: Nutritional parameters were similar in GEP-NEN tumors of different origin. Relapsed disease was associated with decreased BMI. Patients who presented with weight loss at diagnosis had significantly lower overall survival (108 (25-302) vs. 263 (79-136) months). Ghrelin O-acyltransferase (GOAT) enzyme expression was higher in these patients. The prevalence of sarcopenia using CT images reached $87.2 \%$. Mortality was observed only in patients with sarcopenia. Muscle evaluation was correlated with biochemical parameters but not with the expression of ghrelin 
system components. Conclusion: Survival is related to the nutritional status of patients with GEPNENs and also to the molecular expression of some relevant ghrelin system components. Routine nutritional evaluation should be performed in these patients, in order to prescribe appropriate nutritional support, when necessary, for increasing quality of life and improving clinical outcomes.

Keywords: NENs; sarcopenia; CT scan; ghrelin system; nutrition; outcome

\section{Introduction}

Malnutrition is common in cancer patients, which can be a result of the tumor itself but also of the medical or surgical treatment. According to the European Society of Parenteral and Enteral Nutrition (ESPEN), 10-20\% of cancer patients die due to consequences of malnutrition rather than the tumor itself, since malnutrition affects treatment tolerance and response [1]. In this context, an appropriate nutritional screening should be performed at diagnosis and during follow-up in order to establish appropriate therapeutic nutritional strategies [2].

Currently, nutritional interventions cannot be based on the evaluation of body mass index (BMI) due to the increased prevalence of overweight and obesity. Additionally, visceral obesity, sarcopenia and sarcopenic obesity have been identified as adverse factors in cancer patients. Furthermore, the excess of body fat has been also associated with several types of cancer [3,4]. For these reasons, specific tools have been designed for obtaining an initial screening for malnutrition in cancer patients [5]. When screening is positive, an appropriate nutritional evaluation should be performed in order to determine the presence of sarcopenia and start specific nutritional treatment [1].

Sarcopenia is defined as a loss of muscle mass, strength and physical performance, and it is associated with altered amino acid metabolism, increased muscle protein catabolism relative to anabolism, and loss of muscle fibers [6]. Sarcopenia evaluation requires specific techniques that are not regularly performed. Currently, computed tomography (CT) and magnetic resonance imaging (MRI) are considered the gold standards for estimating muscle mass in cancer patients [7], but imaging evaluation of sarcopenia is not routinely performed.

Additionally, in patients with neuroendocrine neoplasms (NENs), nutritional status can be also affected by hormone secretion, which can produce malabsorption, diarrhea, steatorrhea, altered gastrointestinal motility and weight loss, among other symptoms [3]. Despite this, NENs are indolent tumors in several cases. Treatment is usually well-tolerated, and patients present with high survival rates (median survival duration of 41 months) [8]. In consequence, nutritional interventions are not routinely performed in these patients, and studies that specifically evaluate the nutritional status of patients with NENs are limited [9].

The ghrelin system is involved in the regulation of multiple physiological functions, including hormonal secretion, regulation of appetite, gastric motility, body composition and reduced energy expenditure [10-14]. Ghrelin hormone must undergo a unique modification, consisting of the acylation of the third serine residue, which is catalyzed by the ghrelin-Oacyl-transferase (GOAT) enzyme $[13,15]$. This acylated ghrelin represents the active form that binds the canonical ghrelin receptor, GHSR1a, but there is also a truncated receptor GHSR1b, with an unknown ligand and function $[10,16,17]$. Ghrelin is a multifunctional hormone and its expression has been demonstrated in several tissues, especially in glands and in the gastrointestinal tract. Ghrelin plays a role in the regulation of energy balance, gastric acid release, appetite, insulin secretion, gastric motility and the turnover of gastric and intestinal mucosa [18]. In this context, the ghrelin system might play an important role in the regulation of cancer-related processes [19-22] and antagonizing protein breakdown in the catabolic conditions of cancer cachexia [23]. Our group has described its presence in GEP-NENs and some clinical relations with tumor progression [24]. Despite this, its specific role in body composition and/or malnutrition in NEN patients is still unknown. 
In this context, this study was performed in order to evaluate the nutritional status, and presence of sarcopenia, in GEP-NEN patients at diagnosis (using anthropometric, biochemical and imaging techniques), its association with tumor characteristics and its influence on patient survival. Additionally, we aimed to explore some putative relations between nutritional status, sarcopenia and the molecular expression of key components of the ghrelin system in tumor samples, in order to improve the clinical diagnosis of malnutrition and sarcopenia in NEN patients.

\section{Material and Methods}

\subsection{Patients}

This study was conducted in accordance with the Declaration of Helsinki and the Ethics Committee. Patients were treated following national and international clinical practice guidelines [25-27]. Written informed consent was required before inclusion. Data from 104 patients with GEP-NENs were collected (demographic and clinical characteristics of the cohort are summarized in Table 1). Patients were diagnosed between 2001-2014 in a single hospital. Additionally, formalin-fixed paraffin-embedded (FFPE) tumor samples were available for analyses in 63 patients. Patients with hereditary endocrine syndrome were excluded. Clinical records were used to collect full medical history.

\subsection{CT Image Analysis}

CT images at diagnosis were used for this analysis. Two adjacent axial images within the same series, at the third lumbar vertebra, were selected for the analysis of total muscle cross-sectional area $\left(\mathrm{cm}^{2}\right)$ and averaged for each patient. Images were analyzed using a dedicated workstation (Carestream Vue PACS v12.0.0.0700; Carestream Health, Inc., Rochester, NY, USA) that enables specific tissue demarcation using previously reported Hounsfield unit (HU) thresholds. Skeletal muscle tissue was separated according to different density thresholds: a density value of $+35 \mathrm{HU}$ was used to separate fat from muscle tissue and +150 HU to separate muscle from bone tissue [28]. Our observer was trained to correctly identify and quantify lumbar vertebrae and the following muscles: rectus abdominus, abdominal (lateral and oblique), psoas, and paraspinal (quadratus lumborum, erector spinae). The observer was blinded to patient survival status. Muscle area was normalized for height in meters squared $\left(\mathrm{m}^{2}\right)$ and reported as lumbar skeletal muscle index $\left(\mathrm{SMI}, \mathrm{cm}^{2} / \mathrm{m}^{2}\right)$. We used specific cut-offs for sarcopenia (L3 SMI: $38.5 \mathrm{~cm}^{2} / \mathrm{m}^{2}$ for women and $52.4 \mathrm{~cm}^{2} / \mathrm{m}^{2}$ for men) as previously described in a CT-based sarcopenic study for patients with solid malignancies [29].

\subsection{RNA Isolation and Reverse-Transcription}

Total RNA from FFPE samples $(n=63)$ were isolated using the RNeasy-FFPE Kit (Qiagen, Limburg, The Netherlands) according to the manufacturer's instructions, as previously described [24,30]. Quantification of the recovered RNA was assessed using the NanoDrop2000 spectrophotometer (Thermo Fisher Scientific, Wilmington, NC, USA). Total RNA was retrotranscribed to cDNA with the First-Strand Synthesis kit using random hexamer primers (Thermo Fisher Scientific), as previously reported [19,20,31-33].

\subsection{Quantitative Real-Time PCR ( $q P C R)$}

cDNAs were amplified with the Brilliant III SYBR-Green Master Mix (Thermo Fisher Scientific) using the Stratagene Mx3000p system and specific primers for each transcript of interest. Specifically, expression levels (absolute mRNA copy number/50 ng of sample) of ghrelin, In1-ghrelin, GOAT-enzyme, GHSR1a and GHSR1b were measured using previously validated primers [34-36]. RNA expression was adjusted by $18 S$ gene expression [31]. This housekeeping gene was chosen after comparing its expression with BACT by the GeNorm 3.3 software [37]. According to the analysis, $18 S$ was the most reliable housekeeping gene for these samples. 
Table 1. Baseline clinical and biochemical characteristics.

\begin{tabular}{|c|c|}
\hline Characteristic & Total $(n=104)$ \\
\hline $\operatorname{Sex}\left(\sigma^{\top} / q\right)$ & $45.2 / 54.8$ \\
\hline Age at diagnosis (years) & $54.5(52-58)$ \\
\hline Functional tumors & $32.9(27 / 82)$ \\
\hline Incidental tumor & $38.7(29 / 75)$ \\
\hline \multicolumn{2}{|l|}{ Tobacco exposure } \\
\hline No & $31.1(14 / 45)$ \\
\hline Active & $48.9(22 / 45)$ \\
\hline Previous exposure & $20(9 / 45)$ \\
\hline Other neoplasms & $20(18 / 90)$ \\
\hline \multicolumn{2}{|l|}{ Tumor localization } \\
\hline Pancreas & $38.5(40 / 104)$ \\
\hline Stomach & $4.8(5 / 104)$ \\
\hline Small bowel & $21.2(22 / 104)$ \\
\hline Hindgut & $34(35 / 104)$ \\
\hline Other & $2(2 / 104)$ \\
\hline \multicolumn{2}{|l|}{ Nutritional characteristics } \\
\hline Weight loss at diagnosis & $39.7(25 / 63)$ \\
\hline Weight at diagnosis $(\mathrm{Kg})$ & $70(65-78)$ \\
\hline BMI at diagnosis & $27.2(24.5-28.7)$ \\
\hline Metastasis at diagnosis & $49.1(51 / 104)$ \\
\hline Liver & $17.4(8 / 46)$ \\
\hline Spleen & $2.2(1 / 46)$ \\
\hline Lymph nodes & $50(23 / 46)$ \\
\hline Peritoneum & $2.2(2 / 46)$ \\
\hline Multiple invasion & $28.2(13 / 46)$ \\
\hline Relapsed disease & $25.4(17 / 67)$ \\
\hline Disease-free & $75.9(44 / 58)$ \\
\hline Mortality & $34.6(36 / 104)$ \\
\hline \multicolumn{2}{|l|}{ Histologic features } \\
\hline Necrosis & $7.3(9 / 33)$ \\
\hline Multiple tumors & $7.5(4 / 53)$ \\
\hline Peritumoral invasion & $51.8(44 / 85)$ \\
\hline Vascular invasion & $28.2(22 / 78)$ \\
\hline Perineural invasion & $28(21 / 75)$ \\
\hline \multicolumn{2}{|l|}{ Tumor grade } \\
\hline Grade 1 & $33.7(35 / 104)$ \\
\hline Grade 2 & $26.9(28 / 104)$ \\
\hline Grade 3 & $9.6(10 / 104)$ \\
\hline Unknown & $29.8 \%(31 / 104)$ \\
\hline \multicolumn{2}{|l|}{ Biochemical analysis at diagnosis } \\
\hline Lymphocytes & $1520(390-2762)$ \\
\hline Transferrin (mg/dL) & $240(199-262)$ \\
\hline Ferritin $(\mathrm{mg} / \mathrm{dL})$ & $81.7(5-63)$ \\
\hline Albumin (g/dL) & $3.9(1.6-5.6)$ \\
\hline Prealbumin (mg/dL) & $23(9.7-41.6)$ \\
\hline $\mathrm{RCP}(\mathrm{g} / \mathrm{dL})$ & $2.6(1.3-5.4)$ \\
\hline Total cholesterol (mg/dL) & $165(30-206)$ \\
\hline LDL cholesterol (mg/dL) & $95(53-124)$ \\
\hline HDL cholesterol (mg/dL) & $72(15-108)$ \\
\hline
\end{tabular}

Legend: Categorical data are presented as percentage and absolute number. Continuous data are presented as median and $95 \%$ interquartile range.

\subsection{Statistical Analysis}

Between-group comparisons were analyzed by the Mann-Whitney U test (nonparametric data) or the Kruskal-Wallis test (nonparametric data, when we compared more than two groups). Paired analysis was performed with the Student's $t$-test (parametric data) or the Wilcoxon test (nonparametric data). A chi-squared test was used to compare categorical data. Statistical analyses were performed using SPSS statistical software version 20 
and GraphPad Prism version 8. Data are expressed as median \pm interquartile range and percentages. $p$-values $<0.05$ were considered statistically significant.

\section{Results}

\subsection{Patient Population and Clinical Evolution}

One-hundred-and-four patients were included. Most of them were female (54.8\%) with a median age of 54 years at diagnosis and presented mainly with pancreas NENs (38.5\%). Most patients presented with grade 1 tumors (33.7\%); patients with neuroendocrine carcinoma were not included. Almost $40 \%$ of patients presented with weight loss at diagnosis despite a median BMI of $27.2 \mathrm{Kg} / \mathrm{m}^{2}$ (Table 1 ).

At diagnosis, most patients presented with comparable biochemical levels of serum proteins (transferrin, albumin, ferritin, prealbumin and reactive $C$ protein $(\mathrm{RCP})$ ), lipids (total and fractionated cholesterol) and lymphocytes, considering the primary tumor site (Figure 1A). Additionally, the presence of metastasis at diagnosis (almost 50\% of the included patients) tended to be associated with lower BMI and serum LDL cholesterol levels. Furthermore, patients with relapsed disease presented lower BMI whereas patients who were disease-free presented with higher BMI at diagnosis. Serum albumin levels also tended to be associated with increased mortality in NEN patients (Figure 1B).

A)
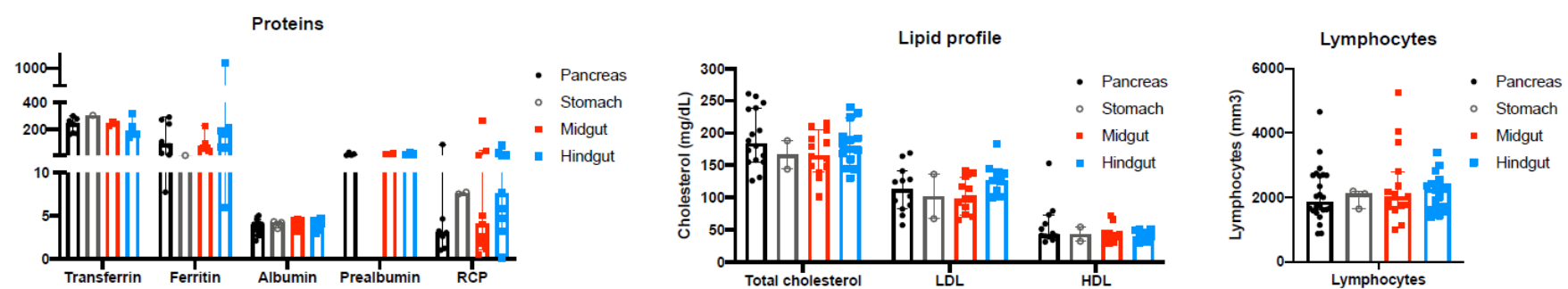

B)
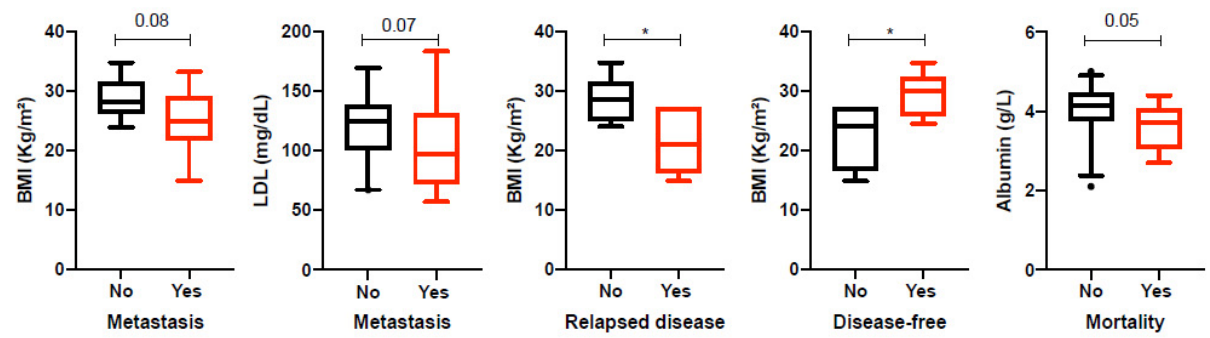

Figure 1. (A) Biochemical parameters for assessing nutritional status in patients with NENs according to the primary tumor site. (B) clinical associations between nutritional parameters and clinical outcome in NEN patients. ${ }^{*}: p<0.05$.

Weight loss at diagnosis was more prevalent in patients with grade 2 tumors, as well as decreased total cholesterol levels and increased RCP (Supplementary Table S1). These results were not statistically significant.

\subsection{Cumulative Survival in NEN Patients Is Associated with Nutritional Parameters}

Patients who presented at diagnosis with weight loss had significantly lower overall survival compared with patients who had not presented this symptom (108 (25-302) vs. 263 (79-136) months) (Figure 2A; Supplementary Table S2A). A similar effect on sur- 
vival was observed when the presence of metastasis at diagnosis was evaluated (136 vs. 245 months; $p=0.05$; Figure 2B). Additionally, patients with decreased albumin at diagnosis tended to present lower overall survival compared with patients with normal serum levels (65 vs. 142 months; $p=0.06$; Figure 2C). Specific data about Log Rank and IQR are presented in Supplementary Table S1A. BMI and other biochemical parameters (transferrin, ferritin, lymphocytes, RCP and cholesterol) were not associated with survival in NEN patients (Supplementary Table S2B; Supplementary Figure S1).

A)
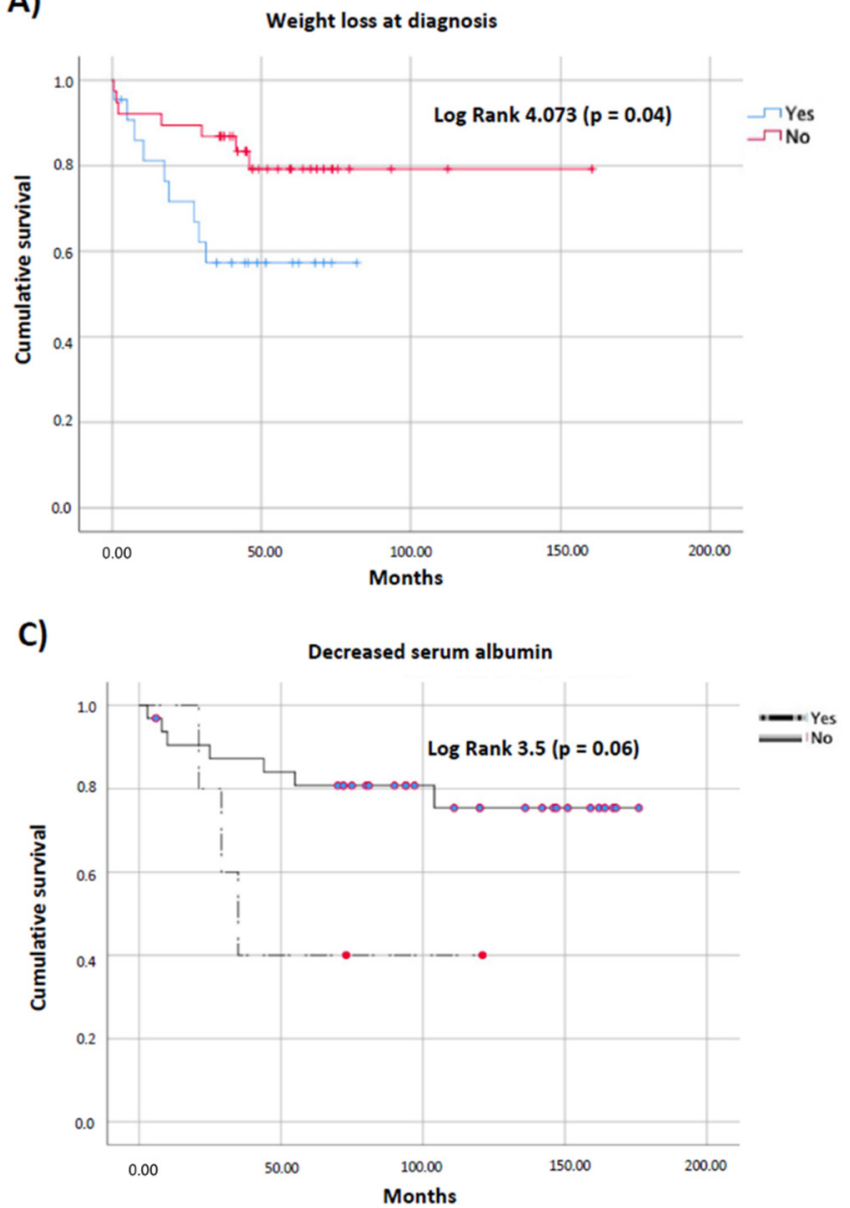

B)

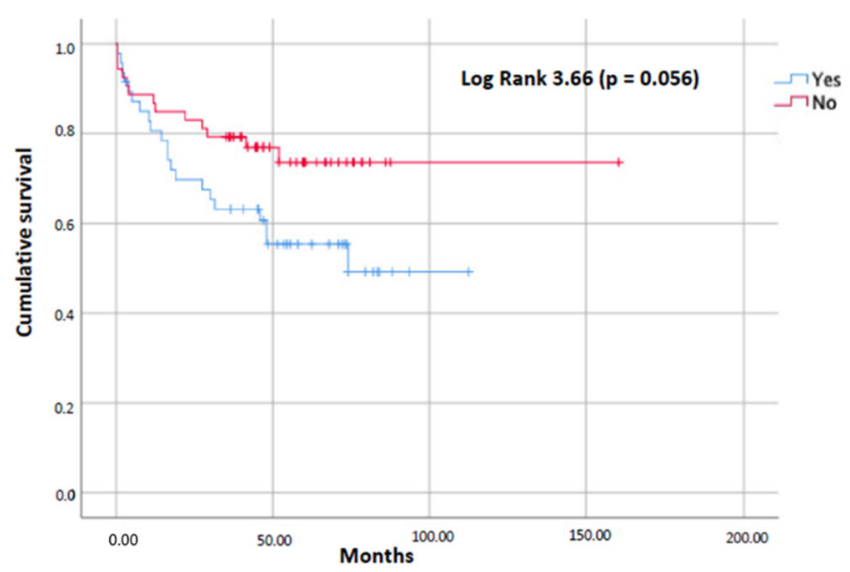

Figure 2. Cumulative survival curves for NEN patients according to the presence of nutrition-related parameters at diagnosis: (A) weight loss; (B) metastasis; (C) decreased serum albumin levels.

3.3. The Molecular Expression of the Ghrelin System and Its Relation to Nutritional Characteristics of NEN Patients

Since weight loss and serum albumin were the most relevant clinical symptoms/biochemical markers associated with survival in NEN patients, we further evaluated their relation to the molecular expression of ghrelin system components in tumor samples of 63 available patients. The expression levels of the GOAT enzyme were significantly increased in patients who presented with weight loss at diagnosis (Figure 3A). Other system components, including ghrelin hormone and the splicing variants In1-ghrelin and GHSR1b, were also increased, but results were not statistically significant. Regarding serum albumin levels, no significant relation was observed between decreased albumin and the molecular expression of ghrelin system components (Figure 3B). 
A)
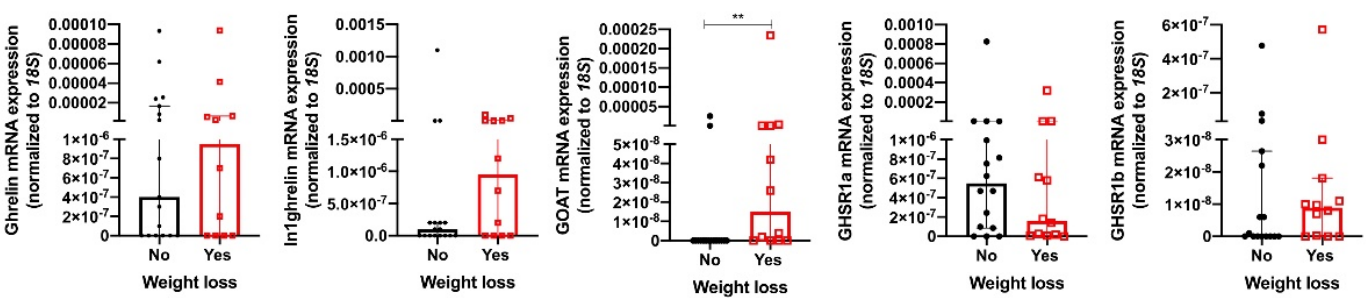

B)
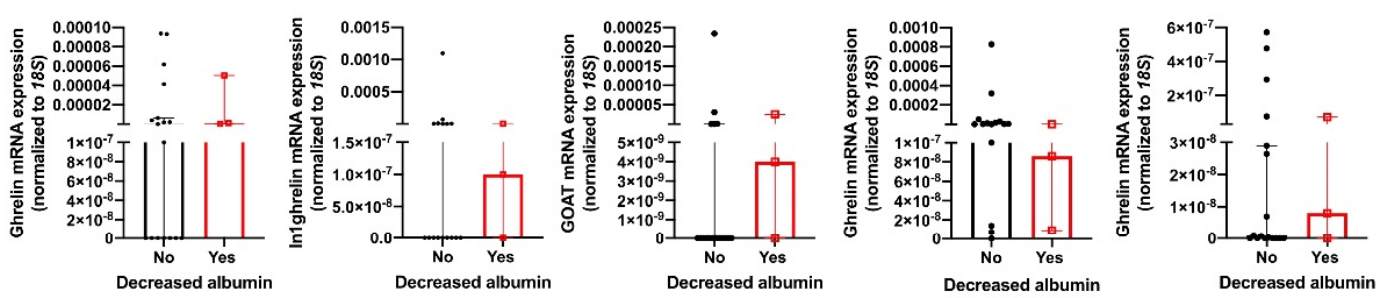

C)

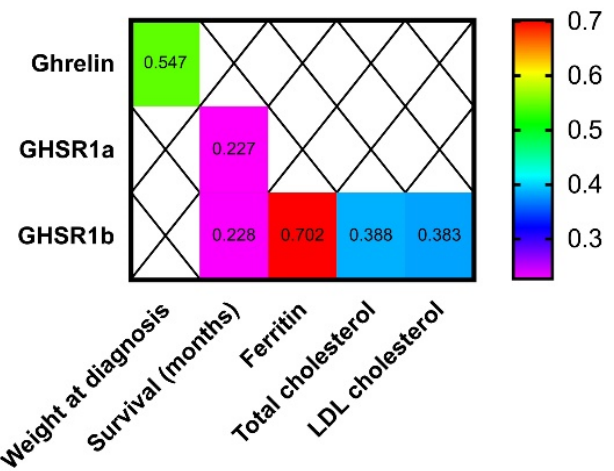

D)

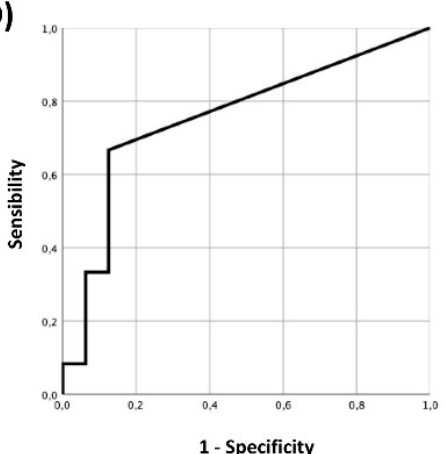

Area

SD

Significance

95\% Cl: Lower limit

$95 \% \mathrm{Cl}$ : Upper limit

Figure 3. Molecular expression of ghrelin system components in NEN tumor samples according to the presence of: (A) weight loss; (B) decreased serum albumin levels; (C) significant clinical correlations between the mRNA expression of some ghrelin system components and nutrition-related parameters in NENs; (D) ROC curve representing GOAT enzyme as marker for identifying NEN patients with weight loss. ${ }^{* *}: p<0.01$.

Additionally, ghrelin expression levels were correlated with weight at diagnosis, while the native and truncated receptors (GHSR1a and GHSR1b, respectively) were associated with the number of survival months. Finally, GHSR1b was also significantly correlated with some biochemical nutritional parameters, including ferritin, total and LDL cholesterol (Figure 3C). Finally, all ghrelin system components were compared using ROC curves for evaluating weight loss in NEN patients, wherein GOAT was the most accurate marker with an AUC of 0.755 (Figure 3D).

\subsection{Sarcopenia at Diagnosis Found to Be Highly Prevalent in NEN Patients Using CT Scan Analysis}

A prevalence of sarcopenia at diagnosis of $87.2 \%$ was observed using CT scan imaging. Serum parameters were significantly correlated with paravertebral, abdominal and psoas areas, as well as with SMI (Figure 4A). Any specific clinical association between muscle areas, densities and SMI was obtained. Mortality occurred only in patients without sarcopenia (Figure 4B), despite the fact that results were not statistically significant. Finally, the expression levels of ghrelin system components were similar in patients with and without sarcopenia defined by decreased SMI (Figure 4C). Decreased SMI was also more prevalent 
in patients with grade 2 tumors (Supplementary Table S1). No relation between sarcopenia and primary tumor site was observed in our cohort (results not shown).

A)

C)

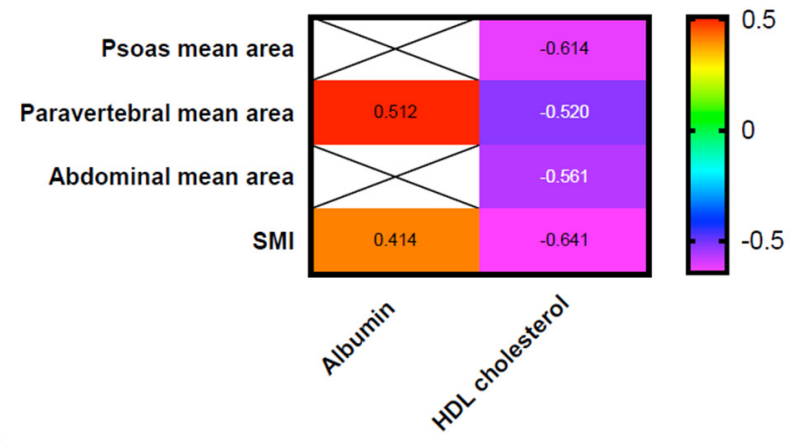

B)

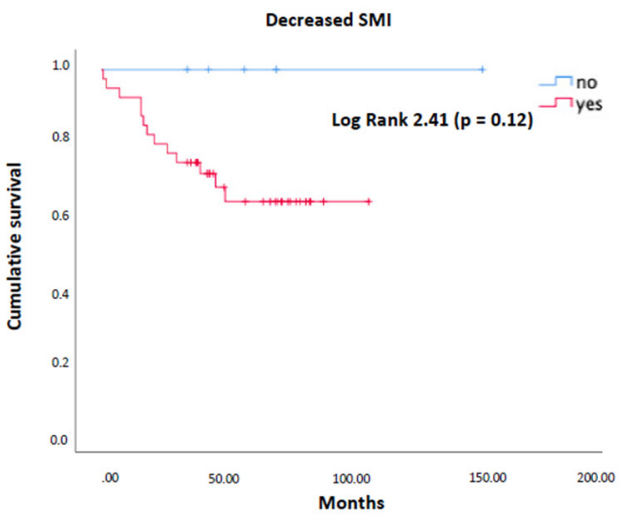

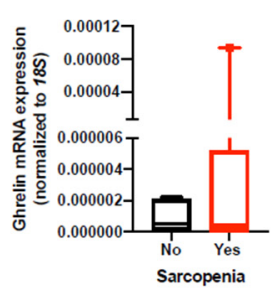

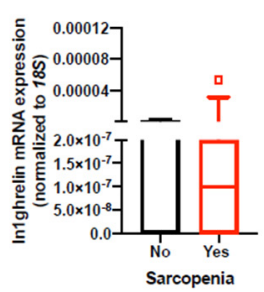

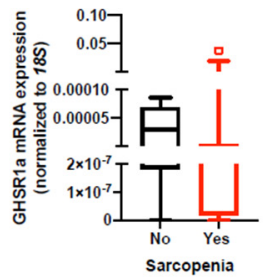

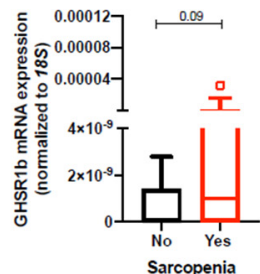

Figure 4. (A) Significant clinical/biochemical correlations between nutritional parameters and CTmeasured muscle characteristics including SMI. (B) Cumulative survival curve for NEN patients according to the presence of sarcopenia at diagnosis using CT imaging. (C) Molecular expression of ghrelin system components in NEN tumor samples according to the presence of sarcopenia at diagnosis using CT scans.

\section{Discussion}

This study aimed to evaluate the nutritional status at diagnosis of patients with GEP-NENs using epidemiological, anthropometrical, biochemical and imaging techniques, and to determine putative relations with the molecular expression of key components of the ghrelin system. There are some studies focused on nutritional aspects in NEN patients [38,39]; however, to our knowledge, this is the first study that comprehensively characterizes the nutritional status and the prevalence of sarcopenia using CT scan imaging for a representative cohort of 104 well-differentiated GEP-NENs. Moreover, we analyzed the impact of nutritional status at diagnosis for disease progression and survival after 7-20 years of follow-up. Furthermore, although some studies have reported the presence of certain components of the ghrelin system in GEP-NENs [21,24,40-42], to the best of our knowledge, its relation to nutritional parameters has not been specifically described in these tumors. Overall, our results revealed that weight loss at diagnosis predicts lower survival in NEN patients. The prevalence of sarcopenia reaches $87 \%$ of patients in our cohort, suggesting that the diagnosis of sarcopenia using CT scans might help to detect these patients early on. Finally, some key components of the ghrelin system, especially the GOAT enzyme, displayed alterations and clinical associations related to the nutritional status of GEP-NEN patients.

Importantly, the American Society for Parenteral and Enteral Nutrition recognized albumin and prealbumin as important factors that correlate with the risk for adverse outcomes in patients, though they should not be used for diagnosing protein-energy malnutrition [43]. This statement is based on the fact that there is an association between inflammation and malnutrition, but not between malnutrition and visceral protein levels [43]. In our cohort we observed that albumin tended to correlate with survival in NEN 
patients, but this fact suggests that the evaluation of serum levels of visceral proteins is not enough for the diagnosis of malnutrition in cancer patients. Furthermore, serum albumin was correlated with muscle area and SMI using CT images, an observation that has been previously described [44], suggesting the importance of its determination in these patients in combination with other techniques for nutritional evaluation.

Weight loss is considered an important factor for diagnosing and classifying malnutrition [45]. Indeed, it has been associated with increased mortality in solid tumors, independently of age, race and tumor stage [46-48]. This study demonstrates decreased survival in NEN patients who presented with weight loss at diagnosis. Related to this, an observational study performed with 203 NEN patients reported increased length of hospital stays and decreased overall survival in patients with malnutrition assessed by screening tools, anthropometric and biochemical variables [49].

Despite malnutrition having been widely reported as a prevalent factor in cancer patients, there is limited data regarding malnutrition prevalence in NEN patients, especially its relation to clinical outcomes, survival and prognosis [38]. Recent publications suggest that at least $21-25 \%$ of NEN patients might present with malnutrition $[49,50]$ such that regular nutritional screening and evaluation in these patients at diagnosis would be appropriate [9]. Moreover, current clinical guidelines suggest the relevance of evaluating muscle mass loss (in combination with BMI, weight loss, food intake and inflammatory status) for diagnosing malnutrition [45], which highlights the necessity of using specific techniques for evaluating muscle mass in cancer patients. Specifically, the use of low skeletal muscle mass as the definition for sarcopenia may help clinicians to make treatment decisions more conveniently and more quickly [51], since BMI does not discriminate the prevalence of sarcopenia or myosteatosis [52].

In this context, it is necessary to use additional tools for evaluating malnutrition in cancer patients, especially in patients with NENs. Since the determination of sarcopenia using CT scans represents the gold standard for evaluating body composition in cancer patients [7], it seems reasonable to evaluate this parameter since most patients have a CT or MRI scan that includes the paravertebral area at diagnosis and during follow-up. Recently, a study performed with 49 metastatic NENs that underwent peptide receptor radionuclide therapy (especially pancreatic and small bowel NENs) reported a prevalence of $67 \%$ sarcopenia and $71 \%$ myosteatosis using CT scans. In this study, progression-free survival was similar in patients with or without sarcopenia, and $12 \%$ of patients died during the follow-up [38]. In contrast, in our cohort, the mortality rate was higher and the prevalence of sarcopenia reached $87 \%$. Importantly, we did not analyze the specific effect of any treatment. In line with this, another retrospective study performed in gastric NENs reported a prevalence of sarcopenia (using CT scans) of $42.8 \%$ [39]. In this study, a higher incidence of sarcopenia in the subgroups of male patients, aged 65 years, with a BMI of $<25 \mathrm{Kg} / \mathrm{m}^{2}$ and a tumor larger than $50 \mathrm{~mm}$ was observed [39]. Importantly this study included only patients with gastric neuroendocrine tumors, neuroendocrine carcinomas and gastric mixed adenoneuroendocrine carcinomas. The authors describe that sarcopenia was not associated with short-term clinical outcomes of these patients (total postoperative complications, surgical complications and systemic complications) but it was an independent risk factor for long-term complications in patients with gastric mixed adenoneuroendocrine carcinomas [39]. Results may differ from our results since we did not evaluate post-surgical complications. Additionally, the number of well-differentiated gastric NENs was limited; thus, the prognostic value of sarcopenia for gastric NENs may be biased. Additionally, this study was conducted in an Asian population with only $23.9 \%$ females [39].

Based on this, it is reasonable to suggest that appropriate nutritional screening should be performed at diagnosis and during follow-up for all patients with NENs, as in other types of cancer [1]. Additionally, nutritional recommendations, including calorie and protein intake should be provided [53], and additional oral nutritional supplementation should be started early on for those patients who are malnourished or at risk of malnutrition [1]. 
In relation to this, ghrelin is an orexigenic gut hormone secreted by several tissues which transmits hunger signals from the peripheral to the central nervous system [54]. It has the potential to increase body weight and body composition through increased appetite, growth hormone secretion and gastric acid secretion. Ghrelin also prevents muscle catabolism, promotes gut motility and regulates metabolism [13,55,56]. These diverse actions suggest that it may disturb the vicious cycle of cachexia through its anabolic, orexigenic and anti-inflammatory effects [13]. There is increasing evidence that suggests that the ghrelin system might be involved in regulating several processes related to cancer progression, especially in metastasis and proliferation [18]. Ghrelin, its native receptor (GHSR1a) and the truncated receptor (GHSR1b), have been described in renal cell carcinomas and neuroendocrine tumors, including pituitary, pancreatic, thyroid, lung, breast, gonadal, prostate, ovarian, oral, gastric and colorectal cancer, using inmunohistochemistry or RT-PCR $[42,57,58]$. Additionally, some studies have demonstrated correlations between the expression of this system, tumor progression and survival outcome in patients with cancer, including renal carcinomas and GEP-NENs [24,58,59]. Ghrelin may also influence cell migration and invasion capacity and consequently metastasis in several types of cancer by the GHSR/PI3K/Akt signaling pathway; in contrast, its role in breast and prostate cancers is controversial $[18,60,61]$.

In this context, in NENs, our and other groups have suggested a role for the ghrelin system in the regulation of GEP-NEN pathophysiology $[11,12,24,40]$. Despite this, to the best of our knowledge, specific studies reporting the expression of ghrelin system components and its nutritional relevance in NEN have not been published yet. Our group previously described a marked overexpression of GOAT in GEP-NEN tumors, which was associated with increased tumor size [24]. Interestingly, in our current study, this ghrelin system component was increased in patients who presented weight loss at diagnosis and consequently decreased survival. Importantly, we did not observe significant changes between the molecular expression of ghrelin system components in patients with or without sarcopenia using CT scans, but these results might be related to the sample size.

This study has some limitation: it is a retrospective cohort study, in which a specific nutritional anthropometric evaluation was not performed, as currently suggested [62]. In consequence, some data, including bioimpedance analysis, are not available. Additionally, due to the number of patients, the effect of specific therapies was not evaluated, and the circulating levels of ghrelin components were not available. Despite this, several strengths of this study should be highlighted, since it includes a well-characterized cohort of welldifferentiated NENs of different origin, with similar proportions of males and females and with sarcopenia evaluation using CT scans, which represent the current gold standard for evaluating body composition in cancer patients [7]. This study also includes patients who were followed-up over a long period of time.

\section{Conclusions}

In summary, we present a characterization of the nutritional status of GEP-NEN patients at diagnosis, the prevalence of CT-based sarcopenia, its relation to survival and the molecular expression of key components of the ghrelin system. Our results demonstrate that sarcopenia is highly prevalent in NEN patients, suggesting the necessity of appropriate nutritional screening/evaluation at diagnosis to identify patients with putatively worse prognoses and to establish specific therapeutic options for reversing malnutrition and improving quality of life and clinical outcomes. Prospective studies that include larger cohorts are still necessary to add to and validate the information provided in this study; circulating levels of ghrelin system components might also provide additional information, since these molecular targets, especially GOAT, could represent putative prognostic markers for GEP-NENs. 
Supplementary Materials: The following are available online at https: / / www.mdpi.com/article/ 10.3390/ cancers14010111/s1, Figure S1. Cumulative survival curves for NEN patients according to nutritional parameters: (A) serum transferrin; (B) serum ferritin; (C) lymphocytes; (D) serum RCP; (E) serum total cholesterol; (F) BMI. Table S1. Prevalence of altered nutritional parameters in patients with NEN at diagnosis according to tumor grade. Table S2. Log rank of cumulative survival curves for NEN patients according to nutritional parameters: (A) weight loss, metastasis and serum albumin levels at diagnosis; (B) BMI and other biochemical nutritional parameters.

Author Contributions: Conceptualization, A.D.H.-M.; Data curation, Y.H.-M. and C.A.T.; Investigation, Y.H.-M., C.A.T., S.L.I., M.J.M.P., A.C.C., R.S.B., J.P.C., M.Á.G.M., M.D.G., R.M.L. and A.D.H.-M.; Supervision, A.D.H.-M. All authors have read and agreed to the published version of the manuscript.

Funding: This work was funded by Instituto de Salud Carlos III: JR19/00050), Junta de Andalucía (PI-0038-2019, BIO-0139). GETNE Junior Grant 2019. Young Investigator's Grant SEEN 2020. SANCYD Research Grant 2021. Ministerio de Ciencia e Innovación (PID2019-105564RB-I00), and CIBERobn. PID2019-105201RB-100; GETNE2019 Research Grant. Additionally, Nestle Healthcare and Nutricia have kindly contributed with the funding of this study. The funders were not involved in the study design, collection, analysis, interpretation of data, the writing of the manuscript or the decision to submit it for publication. CIBER is an initiative of Instituto de Salud Carlos III, Ministerio de Sanidad, Servicios Sociales e Igualdad, Spain.

Institutional Review Board Statement: The study was conducted according to the guidelines of the Declaration of Helsinki, and approved by the Ethics Committee of eina Sofia University Hospital (protocol code 5006 on 27 April 2021).

Informed Consent Statement: Page: 12. Informed consent was obtained from all subjects involved in the study.

Data Availability Statement: The data presented in this study are available in this article and Supplementary Materials.

Conflicts of Interest: The authors have no conflict of interest to declare.

\section{References}

1. Muscaritoli, M.; Arends, J.; Bachmann, P.; Baracos, V.; Barthelemy, N.; Bertz, H.; Bozzetti, F.; Hütterer, E.; Isenring, E.; Kaasa, S.; et al. ESPEN practical guideline: Clinical Nutrition in cancer. Clin. Nutr. 2021, 40, 2898-2913. [CrossRef] [PubMed]

2. Mendes, N.P.; De Barros, T.A.; Rosa, C.D.O.B.; Franceschini, S.D.C.C. Nutritional Screening Tools Used and Validated for Cancer Patients: A Systematic Review. Nutr. Cancer 2019, 71, 898-907. [CrossRef] [PubMed]

3. Gallo, M.; Muscogiuri, G.; Pizza, G.; Ruggeri, R.M.; Barrea, L.; Faggiano, A.; Colao, A.; NIKE Group. The management of neuroendocrine tumours: A nutritional viewpoint. Crit. Rev. Food Sci. Nutr. 2017, 59, 1046-1057. [CrossRef]

4. Byers, T.; Sedjo, R.L. Body fatness as a cause of cancer: Epidemiologic clues to biologic mechanisms. Endocrine-Related Cancer 2015, 22, R125-R134. [CrossRef]

5. Kondrup, J.; Rasmussen, H.H.; Hamberg, O.; Stanga, Z. Nutritional risk screening (NRS 2002): A new method based on an analysis of controlled clinical trials. Clin. Nutr. 2003, 22, 321-336. [CrossRef]

6. Ligibel, J.A.; Schmitz, K.H.; Berger, N.A. Sarcopenia in aging, obesity, and cancer. Transl. Cancer Res. 2020, 9, 5760-5771. [CrossRef]

7. Yip, C.; Dinkel, C.; Mahajan, A.; Siddique, M.; Cook, G.; Goh, V. Imaging body composition in cancer patients: Visceral obesity, sarcopenia and sarcopenic obesity may impact on clinical outcome. Insights Imaging 2015, 6, 489-497. [CrossRef]

8. Man, D.; Wu, J.; Shen, Z.; Zhu, X. Prognosis of patients with neuroendocrine tumor: A SEER database analysis. Cancer Manag. Res. 2018, 10, 5629-5638. [CrossRef]

9. Altieri, B.; Barrea, L.; Modica, R.; Muscogiuri, G.; Savastano, S.; Colao, A.; Faggiano, A. Nutrition and neuroendocrine tumors: An update of the literature. Rev. Endocr. Metab. Disord. 2018, 19, 159-167. [CrossRef]

10. Gahete, M.D.; Rincón-Fernández, D.; Villa-Osaba, A.; Hormaechea-Agulla, D.; Ibañez-Costa, A.; Martínez-Fuentes, A.J.; Gracia-Navarro, F.; Castano, J.P.; Luque, R.M. Ghrelin gene products, receptors, and GOAT enzyme: Biological and pathophysiological insight. J. Endocrinol. 2013, 220, R1-R24. [CrossRef]

11. Chopin, L.K. The ghrelin axis-Does it have an appetite for cancer progression? Endocr. Rev. 2012, 33, 849-891. [CrossRef]

12. Kojima, M.; Hosoda, H.; Date, Y.; Nakazato, M.; Matsuo, H.; Kangawa, K. Ghrelin is a growth-hormone-releasing acylated peptide from stomach. Nature 1999, 402, 656-660. [CrossRef] [PubMed]

13. Muller, T.D. Ghrelin. Mol. Metab. 2015, 4, 437-460. [CrossRef]

14. Kineman, R.D.; Luque, R.M. Evidence that ghrelin is as potent as growth hormone (GH)-releasing hormone (GHRH) in re-leasing GH from primary pituitary cell cultures of a nonhuman primate (Papio anubis), acting through intracellular signaling pathways distinct from GHRH. Endocrinology 2007, 148, 4440-4449. [CrossRef] 
15. Nishi, Y.; Yoh, J.; Hiejima, H.; Kojima, M. Structures and molecular forms of the ghrelin-family peptides. Peptides 2011, 32, 2175-2182. [CrossRef] [PubMed]

16. Gahete, M.D.; Cordoba-Chacon, J.; Hergueta-Redondo, M.; Martínez-Fuentes, A.J.; Kineman, R.D.; Moreno-Bueno, G.; Luque, R.M.; Castaño, J.P. A Novel Human Ghrelin Variant (In1-Ghrelin) and Ghrelin-O-Acyltransferase Are Overexpressed in Breast Cancer: Potential Pathophysiological Relevance. PLoS ONE 2011, 6, e23302. [CrossRef]

17. Leung, P.K. The truncated ghrelin receptor polypeptide (GHS-R1b) acts as a dominant-negative mutant of the ghrelin recep-tor. Cell Signal 2007, 19, 1011-1022. [CrossRef]

18. Lin, T.C.; Hsiao, M. Ghrelin, and cancer progression. Biochim. Biophys. Acta Rev. Cancer 2017, 1868, 51-57.

19. Hormaechea-Agulla, D. Ghrelin O-acyltransferase (GOAT) enzyme is overexpressed in prostate cancer, and its levels are associated with patient's metabolic status: Potential value as a non-invasive biomarker. Cancer Lett. 2016, 383, 125-134. [CrossRef] [PubMed]

20. Herrera-Martínez, A.D.; Gahete, M.D.; Sánchez-Sánchez, R.; Salas, R.O.; Serrano-Blanch, R.; Salvatierra, Á.; Hofland, L.J.; Luque, R.M.; Gálvez-Moreno, M.A.; Castaño, J.P. The components of somatostatin and ghrelin systems are altered in neuroendocrine lung carcinoids and associated to clinical-histological features. Lung Cancer 2017, 109, 128-136. [CrossRef] [PubMed]

21. Luque, R.M. In1-ghrelin, a splice variant of ghrelin gene, is associated with the evolution and aggressiveness of human neuroendocrine tumors: Evidence from clinical, cellular and molecular parameters. Oncotarget 2015, 6, 19619-19633. [CrossRef]

22. Jiménez-Vacas, J.M.; Montero-Hidalgo, A.J.; Gómez-Gómez, E.; Fuentes-Fayos, A.C.; Ruiz-Pino, F.; Guler, I.; Camargo, A.; Anglada, F.J.; Carrasco-Valiente, J.; Tena-Sempere, M.; et al. In1-Ghrelin Splicing Variant as a Key Element in the Pathophysiological Association Between Obesity and Prostate Cancer. J. Clin. Endocrinol. Metab. 2021, 106, e4956-e4968. [CrossRef]

23. Sever, S.; White, D.L.; Garcia, J.M. Is there an effect of ghrelin/ghrelin analogs on cancer? A systematic review. Endocr.-Relat. Cancer 2016, 23, R393-R409. [CrossRef]

24. Herrera-Martinez, A.D. Ghrelin-O-Acyltransferase (GOAT) Enzyme as a Novel Potential Biomarker in Gastroenteropancre-atic Neuroendocrine Tumors. Clin. Transl. Gastroenterol. 2018, 9, 196. [CrossRef] [PubMed]

25. Niederle, B.; Pape, U.-F.; Costa, F.; Gross, D.; Kelestimur, F.; Knigge, U.; Öberg, K.; Pavel, M.; Perren, A.; Toumpanakis, C.; et al. ENETS Consensus Guidelines Update for Neuroendocrine Neoplasms of the Jejunum and Ileum. Neuroendocrinology 2016, 103, 125-138. [CrossRef] [PubMed]

26. Falconi, M. ENETS Consensus Guidelines Update for the Management of Patients with Functional Pancreatic Neuroendo-crine Tumors and Non-Functional Pancreatic Neuroendocrine Tumors. Neuroendocrinology 2016, 103, 153-171. [CrossRef]

27. Delle Fave, G.; O’Toole, D.; Sundin, A.; Taal, B.; Ferolla, P.; Ramage, J.; Ferone, D.; Ito, T.; Weber, W.; Zheng-Pei, Z.; et al. ENETS Consensus Guidelines Update for Gastroduodenal Neuroendocrine Neoplasms. Neuroendocrinology 2016, 103, 119-124. [CrossRef]

28. Lauretani, F.; Russo, C.R.; Bandinelli, S.; Bartali, B.; Cavazzini, C.; Di Iorio, A.; Corsi, A.M.; Rantanen, T.; Guralnik, J.M.; Ferrucci, L. Age-associated changes in skeletal muscles and their effect on mobility: An operational diagnosis of sarcopenia. J. Appl. Physiol. 2003, 95, 1851-1860. [CrossRef]

29. Prado, C.M.; Lieffers, J.R.; McCargar, L.J.; Reiman, T.; Sawyer, M.B.; Martin, L.; Baracos, V.E. Prevalence and clinical implications of sarcopenic obesity in patients with solid tumours of the respiratory and gastrointestinal tracts: A population-based study. Lancet Oncol. 2008, 9, 629-635. [CrossRef]

30. Herrera-Martinez, A.D. Type 2 Diabetes in Neuroendocrine Tumors: Are Biguanides and Statins Part of the Solution? J. Clin. Endocrinol. Metab. 2019, 104, 57-73. [CrossRef] [PubMed]

31. Herrera-Martinez, A.D. Clinical and functional implication of the components of somatostatin system in gastroenteropancre-atic neuroendocrine tumors. Endocrine 2017, 59, 426-437. [CrossRef] [PubMed]

32. Hormaechea-Agulla, D.; Gahete, M.D.; Jiménez-Vacas, J.; Gómez-Gómez, E.; Ibáñez-Costa, A.; L-López, F.; Rivero-Cortés, E.; Sarmento-Cabral, A.; Rosa, O.-S.; Carrasco-Valiente, J.; et al. The oncogenic role of the In1-ghrelin splicing variant in prostate cancer aggressiveness. Mol. Cancer 2017, 16, 146. [CrossRef]

33. Hormaechea-Agulla, D.; Jiménez-Vacas, J.M.; Gómez-Gómez, E.; López, F.L.; Carrasco-Valiente, J.; Valero-Rosa, J.; Moreno, M.M.; Sánchez-Sánchez, R.; Ortega-Salas, R.; Gracia-Navarro, F.; et al. The oncogenic role of the spliced somatostatin receptor sst5TMD4 variant in prostate cancer. FASEB J. 2017, 31, 4682-4696. [CrossRef]

34. Gahete, M.D.; Cordoba-Chacon, J.; Kineman, R.; Luque, R.M.; Castaño, J.P. Role of ghrelin system in neuroprotection and cognitive functions: Implications in Alzheimer's disease. Peptides 2011, 32, 2225-2228. [CrossRef] [PubMed]

35. Ibáñez-Costa, A.; Gahete, M.D.; Rivero-Cortés, E.; Rincón-Fernández, D.; Nelson, R.; Beltrán, M.; De La Riva, A.; Japón, M.A.; Venegas-Moreno, E.; Gálvez, M.Á.; et al. In1-ghrelin splicing variant is overexpressed in pituitary adenomas and increases their aggressive features. Sci. Rep. 2015, 5, 8714. [CrossRef]

36. Rincón-Fernández, D.; Culler, M.D.; Tsomaia, N.; Moreno-Bueno, G.; Luque, R.M.; Gahete, M.D.; Castaño, J.P. In1-ghrelin splicing variant is associated with reduced disease-free survival of breast cancer patients and increases malignancy of breast cancer cells lines. Carcinogenesis 2017, 39, 447-457. [CrossRef]

37. Vandesompele, J.; De Preter, K.; Pattyn, F.; Poppe, B.; Van Roy, N.; De Paepe, A.; Speleman, F. Accurate normalization of real-time quantitative RT-PCR data by geometric averaging of multiple internal control genes. Genome Biol. 2002, 3, RESEARCH0034. [CrossRef]

38. Chan, D.L.; Clarke, S.J.; Engel, A.; Diakos, C.I.; Pavlakis, N.; Roach, P.J.; Bailey, D.L.; Bauer, J.; Findlay, M. Computed tomography (CT)-defined sarcopenia and myosteatosis are prevalent in patients with neuroendocrine neoplasms (NENs) treated with peptide receptor radionuclide therapy (PRRT). Eur. J. Clin. Nutr. 2021, 1-7. [CrossRef] 
39. Wang, J.-B.; Xue, Z.; Lu, J.; He, Q.-L.; Zheng, Z.-F.; Xu, B.-B.; Xie, J.-W.; Li, P.; Xu, Y.; Lin, J.-X.; et al. Effect of sarcopenia on short- and long-term outcomes in patients with gastric neuroendocrine neoplasms after radical gastrectomy: Results from a large, two-institution series. BMC Cancer 2020, 20, 1002. [CrossRef]

40. Papotti, M. Ghrelin-producing endocrine tumors of the stomach and intestine. J. Clin. Endocrinol. Metab. 2001, 86, 5052-5059. [CrossRef] [PubMed]

41. Rindi, G.; Savio, A.; Torsello, A.; Zoli, M.; Locatelli, V.; Cocchi, D.; Paolotti, D.; Solcia, E. Ghrelin expression in gut endocrine growths. Histochem. Cell Biol. 2002, 117, 521-525. [CrossRef]

42. Volante, M. Expression of ghrelin and of the $\mathrm{GH}$ secretagogue receptor by pancreatic islet cells and related endocrine tumors. J. Clin. Endocrinol. Metab. 2002, 87, 1300-1308. [CrossRef]

43. Evans, D.C.; Corkins, M.R.; Malone, A.; Miller, S.; Mogensen, K.M.; Guenter, P.; Jensen, G.L.; The ASPEN Malnutrition Committee. The Use of Visceral Proteins as Nutrition Markers: An ASPEN Position Paper. Nutr. Clin. Pract. 2020, 36, 22-28. [CrossRef]

44. Abbass, T.; Dolan, R.D.; Laird, B.J.; McMillan, D.C. The Relationship between Imaging-Based Body Composition Analysis and the Systemic Inflammatory Response in Patients with Cancer: A Systematic Review. Cancers 2019, 11, 1304. [CrossRef] [PubMed]

45. Cederholm, T. GLIM criteria for the diagnosis of malnutrition-A consensus report from the global clinical nutrition commu-nity. J. Cachexia Sarcopenia Muscle 2019, 10, 207-217. [CrossRef] [PubMed]

46. Shang, L.; Hattori, M.; Fleming, G.; Jaskowiak, N.; Hedeker, D.; Olopade, O.I.; Huo, D. Impact of post-diagnosis weight change on survival outcomes in Black and White breast cancer patients. Breast Cancer Res. 2021, 23, 18. [CrossRef] [PubMed]

47. Nguyen, T.V.; Yueh, B. Weight loss predicts mortality after recurrent oral cavity and oropharyngeal carcinomas. Cancer 2002, 95, 553-562. [CrossRef]

48. Gannavarapu, B.S.; Lau, S.K.; Carter, K.; Cannon, N.A.; Gao, A.; Ahn, C.; Meyer, J.J.; Sher, D.J.; Jatoi, A.; Infante, R.; et al. Prevalence and Survival Impact of Pretreatment Cancer-Associated Weight Loss: A Tool for Guiding Early Palliative Care. J. Oncol. Pract. 2018, 14, e238-e250. [CrossRef] [PubMed]

49. Maasberg, S.; Knappe-Drzikova, B.; Vonderbeck, D.; Jann, H.; Weylandt, K.H.; Grieser, C.; Pascher, A.; Schefold, J.C.; Pavel, M.; Wiedenmann, B.; et al. Malnutrition Predicts Clinical Outcome in Patients with Neuroendocrine Neoplasia. Neuroendocrinology 2015, 104, 11-25. [CrossRef]

50. Qureshi, S.A.; Burch, N.; Druce, M.; Hattersley, A.; Khan, S.; Gopalakrishnan, K.; Darby, C.; Wong, J.L.H.; Davies, L.; Fletcher, S.; et al. Screening for malnutrition in patients with gastro-entero-pancreatic neuroendocrine tumours: A cross-sectional study. BMJ Open 2016, 6, e010765. [CrossRef]

51. Cruz-Jentoft, A.J. Sarcopenia: Revised European consensus on definition and diagnosis. Age Ageing 2019, 48, 601. [CrossRef] [PubMed]

52. Martin, L.; Gioulbasanis, I.; Senesse, P.; Baracos, V.E. Cancer-Associated Malnutrition and CT-Defined Sarcopenia and Myosteatosis Are Endemic in Overweight and Obese Patients. J. Parenter. Enter. Nutr. 2019, 44, 227-238. [CrossRef]

53. Kikut, J.; Jasińska, A.; Pobłocki, J.; Brodowski, J.; Małgorzata, S. Assessment and State of Nutrition of Patients with Gastroenteropancreatic Neuroendocrine Neoplasms. Nutrients 2020, 12, 1961. [CrossRef] [PubMed]

54. Kojima, M.; Kangawa, K. Structure and Function of Ghrelin. Results Probl. Cell Differ. 2008, 46, 89-115. [CrossRef] [PubMed]

55. Chen, C.Y.; Tsai, C.Y. Ghrelin, and motilin in the gastrointestinal system. Curr. Pharm. Des. 2012, 18, 4755-4765. [CrossRef] [PubMed]

56. Chen, J.A. Ghrelin prevents tumour-and cisplatin-induced muscle wasting: Characterization of multiple mechanisms in-volved. J. Cachexia Sarcopenia Muscle 2015, 6, 132-143. [CrossRef]

57. Korbonits, M. The expression of the growth hormone secretagogue receptor ligand ghrelin in normal and abnormal human pituitary and other neuroendocrine tumors. J. Clin. Endocrinol. Metab. 2001, 86, 881-887. [CrossRef]

58. Lin, T.-C.; Liu, Y.-P.; Chan, Y.-C.; Su, C.-Y.; Lin, Y.-F.; Hsu, S.-L.; Yang, C.-S.; Hsiao, M. Ghrelin promotes renal cell carcinoma metastasis via Snail activation and is associated with poor prognosis. J. Pathol. 2015, 237, 50-61. [CrossRef]

59. Volante, M. Ghrelin in fetal thyroid and follicular tumors and cell lines: Expression and effects on tumor growth. Am. J. Pathol. 2003, 162, 645-654. [CrossRef]

60. Duxbury, M.S.; Waseem, T.; Ito, H.; Robinson, M.K.; Zinner, M.J.; Ashley, S.W.; Whang, E.E. Ghrelin promotes pancreatic adenocarcinoma cellular proliferation and invasiveness. Biochem. Biophys. Res. Commun. 2003, 309, 464-468. [CrossRef] [PubMed]

61. Dixit, V.D.; Weeraratna, A.T.; Yang, H.; Bertak, D.; Cooper-Jenkins, A.; Riggins, G.J.; Eberhart, C.G.; Taub, D.D. Ghrelin and the Growth Hormone Secretagogue Receptor Constitute a Novel Autocrine Pathway in Astrocytoma Motility. J. Biol. Chem. 2006, 281, 16681-16690. [CrossRef] [PubMed]

62. Garcia Almeida, J.M. Morphofunctional assessment of patient s nutritional status: A global approach. Nutr. Hosp. 2021, 38, 592-600. [PubMed] 